\title{
Timing of syrinx reduction and stabilization after posterior fossa decompression for pediatric Chiari malformation type I
}

\author{
Silky Chotai, MD, ${ }^{1,2}$ Emily W. Chan, MD, ${ }^{2}$ Travis R. Ladner, MD, ${ }^{2,3}$ Andrew T. Hale, PhD, ${ }^{2}$ \\ Stephen R. Gannon, BS, ${ }^{2}$ Chevis N. Shannon, DrPH, MBA, MPH, ${ }^{1,2,4}$ \\ Christopher M. Bonfield, MD, ${ }^{1,2,4}$ Robert P. Naftel, MD, ${ }^{1,2,4}$ and John C. Wellons, MD, MSPH1,2,4
}

'Department of Neurosurgery, Vanderbilt University Medical Center; ${ }^{2}$ Surgical Outcomes Center for Kids (SOCKs), Monroe Carell Jr. Children's Hospital, Vanderbilt University Medical Center, Nashville, Tennessee; 'Department of Neurosurgery, Icahn School of Medicine at Mount Sinai, New York, New York; and 4Division of Pediatric Neurosurgery, Monroe Carell Jr. Children's Hospital, Vanderbilt University Medical Center, Nashville, Tennessee

OBJECTIVE The aim of this study was to determine the timeline of syrinx regression and to identify factors mitigating syrinx resolution in pediatric patients with Chiari malformation type I (CM-I) undergoing posterior fossa decompression (PFD).

METHODS The authors conducted a retrospective review of records from pediatric patients (< 18 years old) undergoing PFD for the treatment of CM-I/syringomyelia (SM) between 1998 and 2015. Patient demographic, clinical, radiological, and surgical variables were collected and analyzed. Radiological information was reviewed at 4 time points: 1) pre-PFD, 2) within 6 months post-PFD, 3) within 12 months post-PFD, and 4) at maximum available follow-up. Syrinx regression was defined as $\geq 50 \%$ decrease in the maximal anteroposterior syrinx diameter (MSD). The time to syrinx regression was determined using Kaplan-Meier analysis. Multivariate analysis was conducted using a Cox proportional hazards model to determine the association between preoperative, clinical, and surgery-related factors and syrinx regression.

RESULTS The authors identified 85 patients with CM-I/SM who underwent PFD. Within 3 months post-PFD, the mean MSD regressed from $8.1 \pm 3.4 \mathrm{~mm}$ (preoperatively) to $5.6 \pm 2.9 \mathrm{~mm}$ within 3 months post-PFD. Seventy patients $(82.4 \%)$ achieved $\geq 50 \%$ regression in MSD. The median time to $\geq 50 \%$ regression in MSD was 8 months $(95 \% \mathrm{Cl} 4.2-11.8$ months). Using a risk-adjusted multivariable Cox proportional hazards model, the patients who underwent tonsil coagulation $(n=20)$ had a higher likelihood of achieving $\geq 50 \%$ syrinx regression in a shorter time (HR 2.86, 95\% Cl 1.2-6.9; $p$ $=0.02)$. Thirty-six (75\%) of 45 patients had improvement in headache at 2.9 months (IQR 1.5-4.4 months).

CONCLUSIONS The maximum reduction in syrinx size can be expected within 3 months after PFD for patients with $\mathrm{CM}-\mathrm{I}$ and a syrinx; however, the syringes continue to regress over time. Tonsil coagulation was associated with early syrinx regression in this cohort. However, the role of surgical maneuvers such as tonsil coagulation and arachnoid veil identification and sectioning in the overall role of $\mathrm{CM}-\mathrm{I}$ surgery remains unclear.

https://thejns.org/doi/abs/10.3171/2020.2.PEDS19366

KEYWORDS Chiari malformation; CM-I; syrinx; regression

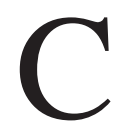
HIARI malformation type I (CM-I) is defined as herniation of the cerebellar tonsils more than $3 \mathrm{~mm}$ below the plane of the foramen magnum. Approximately $14 \%-84 \%$ of children with CM-I have an associated syrinx,${ }^{1-3}$ and a number of theories have been proposed to explain the relationship between CM-I and syringomyelia (SM) ${ }^{4-14}$ The most commonly accepted theory is that the decreased volume of the posterior fossa in patients with CM-I forces CSF, which would normally be free to move through the foramen magnum, to be retained in the brain, leading to an increased craniospinal pressure gradient. In addition, the low-lying cerebellar tonsils may obstruct the fourth ventricular outlet foramina, impeding CSF movement into the spinal subarachnoid space and forcing CSF

ABBREVIATIONS CM-I = Chiari malformation type I; MSD = maximal anteroposterior syrinx diameter; PFD = posterior fossa decompression; SM = syringomyelia. SUBMITTED July 4, 2019. ACCEPTED February 18, 2020.

INCLUDE WHEN CITING Published online April 24, 2020; DOI: 10.3171/2020.2.PEDS19366. 
into the central canal. With each cardiac cycle, systole forces CSF out of the cranium, and the progressive fluid accumulation within the central canal results in the formation of a syrinx. ${ }^{30}$ Therefore, the primary aim of surgical treatment in patients with CM-I is to relieve the pressure at the craniovertebral junction, most commonly by posterior fossa decompression (PFD). Thus, expansion of the posterior fossa space and creation of an artificial cisterna magna relieves the craniospinal pressure dissociation, resulting in regression of syrinx size and improvement of the compression-associated symptoms.

Numerous studies have reported symptomatic improvement following PFD for CM-I, with PFD indicating a causal relationship between CM-I and SM. ${ }^{6,15-22,29,31}$ However, the time course of syrinx resolution post-PFD is poorly understood. The range of time to syrinx regression varies from 3 months to 21 months after PFD in series with both adult and pediatric patients. ${ }^{23-25}$ In this study, we had 3 goals: 1) to investigate the time course of syrinx reduction and stabilization post-PFD, 2) to determine the time course of symptom improvement post-PFD, and 3) to describe demographic, clinical, radiological, and surgical variables associated with syrinx regression in pediatric patients with CM-I/SM.

\section{Methods \\ Data Collection}

Institutional review board approval was obtained from Vanderbilt University Medical Center. A retrospective chart review was conducted to identify pediatric patients ( $<18$ years old) undergoing PFD for the treatment of CM-I with SM between 1998 and 2015. Patients were identified using an ICD-9 diagnosis code of 348.4. Patients with CM-I, but without SM, those with an isolated syrinx, and patients without any follow-up imaging data were excluded from the study. All patients underwent suboccipital decompression of the foramen magnum and $\mathrm{C} 1$ laminectomy with or without duraplasty.

Demographic, clinical, radiological, and surgical variables were collected. Patient-reported symptoms included headaches and other symptoms (dysesthesia, sensory loss, weakness, and difficulty urinating). Imaging variables included tonsil size, syrinx length, maximal anteroposterior syrinx diameter (MSD), $\mathrm{pB}-\mathrm{C} 2$ line (the $\mathrm{pB}-\mathrm{C} 2$ line was divided into grade $0[<3 \mathrm{~mm}]$ and grade $\mathrm{I}[\geq 3 \mathrm{~mm}])$ and cerebellar tonsil herniation (tonsil ectopia) were recorded and analyzed. Surgical variables including PFD with or without duraplasty, arachnoid veil occlusion of the fourth ventricle (determined by intraoperative observation and documentation in the operative note), arachnoid veil transection, and utilization of tonsillar coagulation.

\section{Outcomes}

The primary outcome of interest was syrinx regression or resolution. Syrinx regression was defined as $\geq 50 \%$ decrease in the MSD. The MSD was recorded preoperatively, within 6 months postoperatively, within 12 months postoperatively, and at maximum available imaging follow-up. The imaging data available at the time of the follow-up time point were used to establish the MSD. Change in the
MSD from baseline at each follow-up point was calculated and graded as $\geq 50 \%$ regression in the MSD, complete resolution of syrinx, $<50 \%$ regression in the MSD, or no change or increase in the MSD. The time to syrinx regression was defined as the earliest MRI demonstrating $\geq 50 \%$ regression in the MSD. The secondary outcomes included improvement of symptoms, which was defined as complete resolution, improvement, no significant change, or worsening of symptoms. Complications and return to the OR were also reported for all patients and for each surgeon. All the follow-up data and time points were from initial surgery. If the patient had a complication or reoperation, these could have affected final outcomes. Therefore, complication/reoperation was adjusted in the multivariable analysis.

\section{Statistical Analysis}

Means and standard deviations for continuous variables and frequency for categorical variables were computed. Kaplan-Meier analysis was used to determine the time to syrinx regression. Multivariate analysis was conducted using a Cox proportional hazards model to examine the association of preoperative, clinical, and surgery-related factors and syrinx regression. Criterion for statistical significance was set a priori at $\mathrm{p}<0.05$. Analysis was performed using SPSS version 20 (IBM Corp.).

\section{Results}

\section{Patient Cohort}

We identified 111 patients with CM-I and a syrinx who underwent PFD surgery. Of those, 85 patients with complete preoperative and postoperative imaging data were included in the analysis. All surgeries prior to 2012 were performed by one surgeon who is deceased. The mean age of our cohort was $9.3 \pm 4.1(\mathrm{SD})$ years, $43 \%$ of patients were male, and $88 \%$ of patients were Caucasian (Table 1). Most patients $(94.1 \%, \mathrm{n}=80)$ had duraplasty performed during PFD, and $24.7 \%(\mathrm{n}=21)$ underwent tonsillar coagulation. During this time epoch, 55 patients were operated on by surgeon 1; 22 patients were operated on by surgeon 2; and surgeons 3, 4, and 5 had 1, 1, and 6 patients, respectively. Of 55 patients operated on by surgeon 1,5 underwent bone-only decompression, and 50 underwent bone decompression, dural opening, and duraplasty; no arachnoid dissection was performed. Surgeon 2 had 22 patients who underwent bone decompression, dural opening, arachnoid opening, and tonsillar coagulation; when noted intraoperatively, the arachnoid veil was opened, and CSF flow from the fourth ventricle was observed. In all patients who underwent duraplasty, pericranial graft was placed. All patients with bony decompression underwent scoring of the outer dural layer.

\section{Imaging Evidence of Syrinx Regression Over Time}

Figure 1 provides a preoperative T2-weighted MR image that shows cerebellar tonsil herniation and a cervical syrinx (Fig. 1 left), and a 1-year post-PFD follow-up T2weighted MR image demonstrating the rounded shape of the tonsils, artificial cisterna magna, and a reduction in syrinx size (Fig. 1 right). 
TABLE 1. Demographic, clinical, radiological, and surgical variables of our study cohort

\begin{tabular}{|c|c|}
\hline Variable & Value \\
\hline No. of patients & 85 \\
\hline \multicolumn{2}{|l|}{ Demographics } \\
\hline Age at surgery (yrs) & $9.3 \pm 4.1$ \\
\hline Male sex & $37(43 \%)$ \\
\hline \multicolumn{2}{|l|}{ Race } \\
\hline Caucasian & $75(88 \%)$ \\
\hline Non-Caucasian & $10(12 \%)$ \\
\hline \multicolumn{2}{|l|}{ Clinical symptoms } \\
\hline Headache & $47(55.3 \%)$ \\
\hline \multicolumn{2}{|l|}{ Chiari Severity Index } \\
\hline Grade 1 & $25(29.4 \%)$ \\
\hline Grade 2 & $5(5.9 \%)$ \\
\hline Grade 3 & $55(64.7 \%)$ \\
\hline \multicolumn{2}{|l|}{ Imaging features } \\
\hline $\mathrm{pB}-\mathrm{C} 2$ line $(\mathrm{mm})$ & $6.5 \pm 2.1$ \\
\hline \multicolumn{2}{|l|}{$\mathrm{pB}-\mathrm{C} 2^{*}$} \\
\hline Grade 0 & $5(5.9 \%)$ \\
\hline Grade I & $80(94.1 \%)$ \\
\hline $\operatorname{MSD}(\mathrm{mm})$ & $8.1 \pm 3.4$ \\
\hline Tonsil ectopia (mm) & $11.7 \pm 5.1$ \\
\hline \multicolumn{2}{|l|}{ Surgical variables } \\
\hline Duraplasty & $80(94.1 \%)$ \\
\hline Arachnoid veil occluding 4th ventricle & $15(19 \%)$ of 80 \\
\hline Arachnoid veil transected & $15(19 \%)$ of 80 \\
\hline Tonsil coagulation & $21(24.7 \%)$ \\
\hline Duration of surgery (mins) & $127.2 \pm 49.8$ \\
\hline Estimated blood loss (ml) & $27.1 \pm 26.3$ \\
\hline Length of hospital stay (days) & $2.3 \pm 0.9$ \\
\hline \multicolumn{2}{|l|}{ Surgeon } \\
\hline 1 & $55(64.7 \%)$ \\
\hline 2 & $22(25.9 \%)$ \\
\hline 3 & $1(1.2 \%)$ \\
\hline 4 & $1(1.2 \%)$ \\
\hline 5 & $6(7.1 \%)$ \\
\hline
\end{tabular}

Values are presented as the number (\%) of patients or the mean \pm SD.

* The $\mathrm{pB}-\mathrm{C} 2$ line was divided into grade $0(<3 \mathrm{~mm})$ and grade I $(\geq 3 \mathrm{~mm})$.

The mean preoperative MSD was $8.1 \pm 3.4 \mathrm{~mm}$. Within 3 months post-PFD, the mean MSD regressed to $5.6 \pm$ $2.9 \mathrm{~mm}$ and remained at $5.6 \pm 3.1 \mathrm{~mm}$ at a median of 10 months (range 6-12 months) post-PFD. At a median of 34 months post-PFD (maximum 146 months), the mean MSD was $4.4 \pm 2.5 \mathrm{~mm}$, indicating that syringes can continue to regress over long periods of time. Forty-seven patients had imaging follow-up at more than 12 months after surgery. Figure 2 demonstrates the improvement in syringes for each patient. The median time to $\geq 50 \%$ regression in the MSD was 8 months (95\% CI 4.2-11.8 months) (Fig. 3 ). Seventy patients $(82.4 \%)$ achieved $\geq 50 \%$ regression in MSD. Eight patients achieved complete syrinx resolution
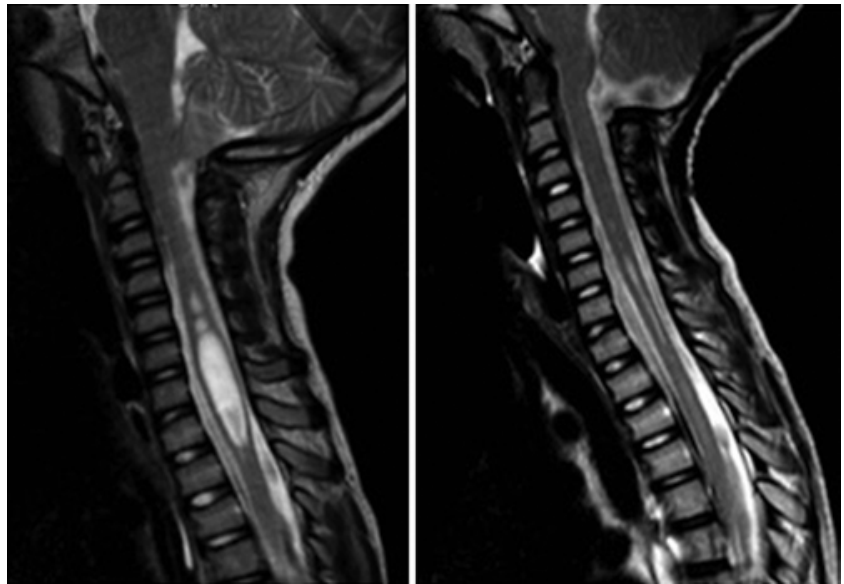

FIG. 1. Left: Preoperative T2-weighted MR image showing cerebellar tonsil herniation and a cervical syrinx. Right: Postoperative 1-year follow-up T2-weighted MR image after PFD, demonstrating the rounded shape of the tonsils, artificial cisterna magna, and reduction in syrinx size.

at a median of 12 months (range 4-70 months). Fifteen patients did not achieve $\geq 50 \%$ syrinx regression; 9 had some improvement in the MSD, and 5 patients demonstrated no change or worsening of the MSD (1 patient). Of those 15 patients, 14 patients underwent duraplasty and 1 underwent bone-only decompression.

\section{Symptom Improvement}

Forty-seven patients had preoperative headache, and 59 patients had other associated symptoms, including upperextremity $(n=15)$ or lower-extremity $(n=14)$ tingling, numbness, weakness, dysphagia $(\mathrm{n}=4)$, sleep apnea $(\mathrm{n}=$ $3)$, paresthesia $(n=5)$, urinary incontinence $(n=4)$, gait imbalance $(n=7)$, blurry vision $(n=5)$, seizures $(n=3)$, and pseudoseizures $(\mathrm{n}=1)$. Among patients with headache, $76.6 \%(\mathrm{n}=36)$ of patients had improvement in headache after PFD. Nearly half $(46.8 \%)$ of the patients had complete resolution, and $29.8 \%$ had some improvement in headache. Seventy-eight percent of patients had improvement or resolution of other preoperative symptoms (Table 2). The median time to improvement of headache was 2.9 months (IQR 1.5-4.4 months), and the median time to improvement of other symptoms was 2.5 months (IQR $1.5-4.9$ months).

\section{Complications and Return to the OR}

A total of 10 complications were noted (surgeon 1: $\mathrm{n}=$ 10; surgeons 2-5: $\mathrm{n}=0$ ). Three patients developed aseptic meningitis, 4 patients had a CSF leak, 1 patient had hydrocephalus, and 2 patients had continued headaches. Three patients required the placement of a postoperative ventriculoperitoneal shunt for CSF leaks $(n=2)$ or hydrocephalus $(\mathrm{n}=1)$. Seven patients had a persistent syrinx and associated symptoms (surgeon $1, \mathrm{n}=4$; surgeon $2, \mathrm{n}$ $=3$ ). Four patients underwent the placement of a syringosubarachnoid shunt, and 3 underwent redo suboccipital decompression. Among these 3 patients, 1 patient, who had undergone PFD with duraplasty, had an overgrown $\mathrm{C} 1 \mathrm{arch}$, which was dissected during redo decompression, 

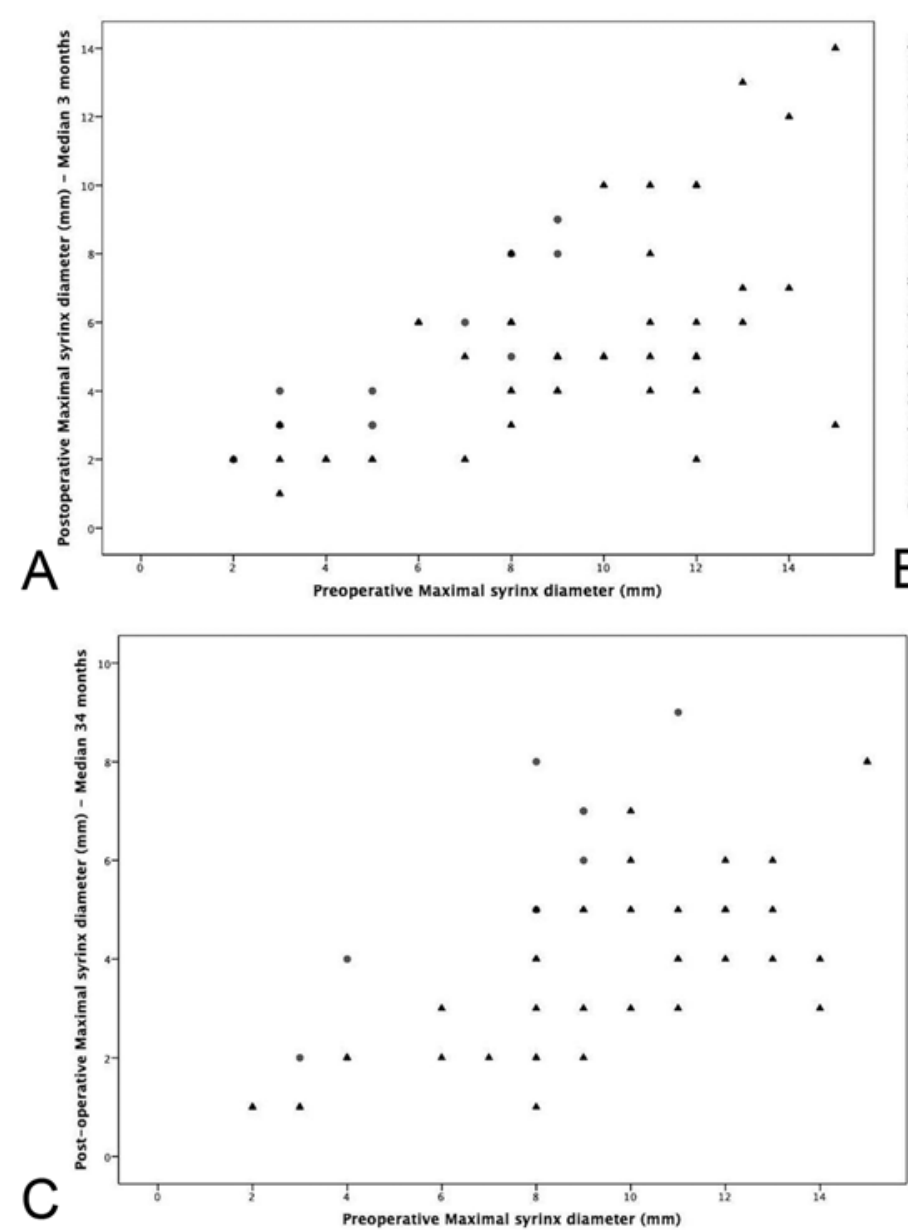

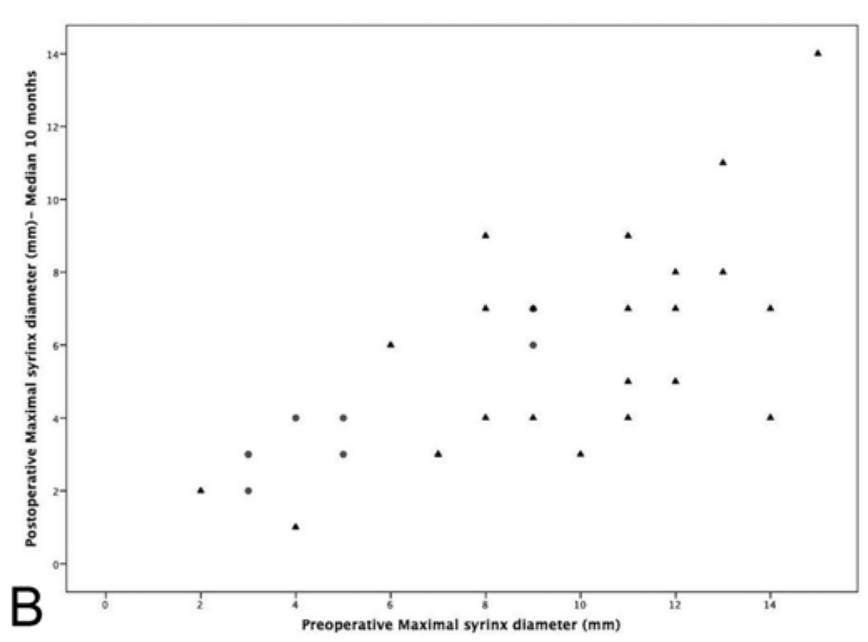

FIG. 2. Scatterplots demonstrating the change in the MSD within 6 months (median 3 months) (A), within 12 months (median 10 months) (B), and at maximum available follow-up (median 34 months) (C) after surgery for $\mathrm{CM}$-I with a syrinx. and the dura was not reopened. Another patient, who had undergone PFD with duraplasty but without coagulation of the tonsil, underwent arachnoid dissection and coagulation of the tonsil. The third patient, who had undergone

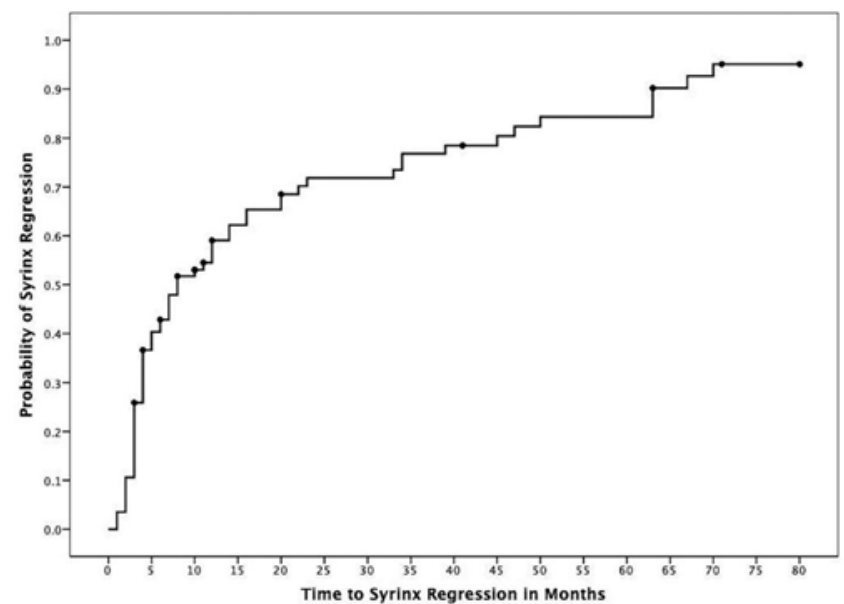

FIG. 3. Kaplan-Meier curve demonstrating median time to regression of syrinx ( $\geq 50 \%$ improvement in the MSD).
PFD with duraplasty and tonsil coagulation during the index surgery, was found to have scarring around the coagulated tonsil during redo surgery, requiring subpial resection of the tonsil.

\section{Multivariate Analysis}

As shown by risk-adjusted multivariable Cox proportional hazards model, the patients who had tonsil coagulation had a higher likelihood of achieving $\geq 50 \%$ syrinx regression in a shorter time compared to those who did not have tonsil coagulation (HR 3.227, 95\% CI 1.27-8.17; $\mathrm{p}=$ 0.0014 ) (Table 3 ). Within the limits of variables included in the model, no other factors were associated with syrinx regression following PFD with or without duraplasty (Table 3). The median time to $\geq 50 \%$ syrinx regression for patients who underwent tonsil coagulation was 3 months (IQR 3-14 months) compared to 12 months (IQR 4-47 months) for patients who did not undergo tonsil coagulation $(\mathrm{p}=0.002)$.

\section{Discussion}

In this study, we investigate the time course of syrinx resolution and symptom improvement after PFD surgery for CM-I. We observed that most patients achieved more 
TABLE 2. Radiological and clinical outcomes after PFD for CM-I with SM

\begin{tabular}{|c|c|}
\hline Variable & Value \\
\hline \multicolumn{2}{|l|}{ Radiological outcomes } \\
\hline MSD w/in 6 mos postop, mm & $5.4 \pm 2.9$ \\
\hline MSD w/in 1 yr postop, mm & $5.5 \pm 2.9$ \\
\hline MSD at maximum follow-up, mm & $4.1 \pm 2.1$ \\
\hline$\geq 50 \%$ regression in MSD & $70(82.4 \%)$ \\
\hline \multicolumn{2}{|l|}{ Clinical outcomes $(n=47)$} \\
\hline \multicolumn{2}{|l|}{ Headache } \\
\hline Complete resolution & $22(46.8 \%)$ \\
\hline Regression & $14(29.8 \%)$ \\
\hline No significant change & $3(6.4 \%)$ \\
\hline Progression & $9(19.1 \%)$ \\
\hline \multicolumn{2}{|l|}{ Overall symptom improvement } \\
\hline Improved or resolved & $67(78.8 \%)$ \\
\hline No change & $18(21.1 \%)$ \\
\hline \multicolumn{2}{|l|}{ Complications ( $n=10[11.8 \%])$} \\
\hline CSF leak & $4(4.5 \%)$ \\
\hline Continued headaches & $2(2.3 \%)$ \\
\hline Hydrocephalus & $1(1.1 \%)$ \\
\hline Meningitis & $3(3.5 \%)$ \\
\hline \multicolumn{2}{|l|}{ Indication for return to $\mathrm{OR}(\mathrm{n}=10)$} \\
\hline Persistent syrinx (syringosubarachnoid shunt) & $4(4.5 \%)$ \\
\hline Redo suboccipital decompression & $3(3.4 \%)$ \\
\hline \multicolumn{2}{|l|}{ Redo bone-only decompression $(n=1)$} \\
\hline \multicolumn{2}{|l|}{ Coagulation of tonsil $(n=1)$} \\
\hline \multicolumn{2}{|l|}{ Subpial resection of tonsil $(n=1)$} \\
\hline Ventriculoperitoneal shunt & $3(3.4 \%)$ \\
\hline \multicolumn{2}{|l|}{ CSF leak $(n=2)$} \\
\hline Hydrocephalus $(n=1)$ & \\
\hline
\end{tabular}

Data are presented as the mean \pm SD or as the number (\%) of patients.

than $50 \%$ regression in syrinx size by 8 months postoperatively. Tonsil coagulation may be an important operatordependent variable that can lead to early syrinx regression. Although, syringes continue to regress over time, which was up to 12.2 years in the present study, the maximal amount of syrinx resolution can be expected at a median of 3 months after surgery. Therefore, longer-term imaging studies might not be required in all patients undergoing PFD for CM-I with a syrinx.

Previous studies have reported the time course of syrinx improvement after PFD in CM-I patients. ${ }^{24-27,32}$ In a prospective study, Wetjen et al. reported a median time of 3.6 months to $\geq 50 \%$ syrinx regression. In their study, $52 \%$ and $59 \%$ of patients had continuing dysesthesia and sensory loss, respectively, and all patients were adults; therefore the results cannot be directly applied to the pediatric population. ${ }^{25} \mathrm{Wu}$ and colleagues reported 44 pediatric patients who underwent PFD for CM-I, SM, and scoliosis. Syrinx improvement was reported in $82 \%$ of patients by 6 months post-PFD and in $98 \%$ of patients over the course of follow-up. ${ }^{27}$ The authors defined syrinx resolution as a
$>20 \%$ decrease in the MSD, a much less stringent criterion than that included here ( $\geq 50 \%$ decrease in the MSD). Kennedy et al. performed a retrospective review of 68 children who underwent PFD without duraplasty and observed a median time to syrinx resolution of 21 months, which was delayed compared to that seen in our study and other studies with patients primarily undergoing duraplasty. ${ }^{24}$ In our study, PFD with or without duraplasty could not be analyzed because only 5 patients underwent PFD without duraplasty.

In a retrospective review of 171 pediatric patients with CM-I and SM, $25 \%$ of patients underwent tonsil cautery and had significantly higher odds (6.1) of their syrinx improving. ${ }^{26}$ However, the authors did not evaluate the effect of this technique on timing of syrinx regression. In our study, tonsil coagulation was performed in $27 \%$ of patients. In a risk-adjusted multivariable analysis, the tonsil coagulation was independently associated with early regression of syrinx. One of the theories on the pathogenesis for development and progression of syrinx in CM-I patients suggests that SM is produced by the action of cerebellar tonsils, which partially occlude the subarachnoid space at the foramen magnum causing a pistonlike effect. It is possible that with each systolic pressure wave, the tonsils are pushed inferiorly, causing elevated pressures in the spinal cord, which forces CSF into the central canal along the perivascular and interstitial spaces and leads to syrinx formation. Therefore, coagulation of the tonsils may assist in immediate reduction of pressure on the spinal cord, subsequently inducing syrinx regression. Interestingly, although the radiological improvement in the syrinx was seen earlier in patients undergoing tonsil coagulation, the clinical symptom improvement was similar in patients with and without tonsil coagulation. As is well established, many children with CM-I and a syrinx have a smaller posterior fossa. ${ }^{1,28}$ Therefore, the PFD results in expansion of the posterior fossa volume and creation of an artificial cisterna magna, which relieves the craniospinal pressure dissociation, leading to improvement of the clinical symptoms. It is unclear if this is independent of the radiological syrinx improvement. Therefore, the role of surgical maneuvers such as tonsil coagulation and arachnoid veil transection remains to be seen. Further studies are needed to determine the impact of specific surgical approaches accompanying PFD in patients with CM-I/SM.

Our study is not without limitations. First, this is a single-center study, which limits its generalizability to the surgeons practicing there. Second, the operations were done mainly by two surgeons, separated in time, with a short overlap. There were technical differences in the procedure performed. The first surgeon tended toward opening the dura, keeping the arachnoid intact when possible, and sewing in a dural allograft. The second surgeon explored for an arachnoid veil, coagulated the cerebellar tonsils, and used pericranium for the dural patch. There is no clear data that a difference in duraplasty techniques yields a difference in outcomes, but further investigations by our group are forthcoming. Next, the results of the riskadjusted analysis should be interpreted considering the limit of variables entered in the model. Other confounders not adjusted in the model might change the effect of tonsil 
TABLE 3. Multivariable Cox proportional hazards model for time to regression of syrinx $(\geq 50 \%$ improvement in MSD)

\begin{tabular}{|c|c|c|c|c|c|}
\hline \multirow[b]{2}{*}{ Variable } & \multirow[b]{2}{*}{ Wald Chi-Square } & \multirow[b]{2}{*}{$p$ Value } & \multirow[b]{2}{*}{$\mathrm{HR}$} & \multicolumn{2}{|c|}{$95 \% \mathrm{Cl}$ for $\mathrm{HR}$} \\
\hline & & & & Lower & Upper \\
\hline \multicolumn{6}{|l|}{ Demographics } \\
\hline Age at surgery & 1.265 & 0.261 & 1.040 & 0.971 & 1.114 \\
\hline Sex: male vs female & 0.050 & 0.822 & 0.932 & 0.518 & 1.721 \\
\hline Chiari Severity Index & 0.058 & 0.810 & 0.962 & 0.703 & 1.318 \\
\hline \multicolumn{6}{|l|}{ Imaging variables } \\
\hline Preop MSD (mm) & 1.066 & 0.975 & 1.066 & 0.977 & 1.163 \\
\hline $\mathrm{pB}-\mathrm{C} 2(\mathrm{~mm})$ & 0.001 & 0.975 & 0.998 & 0.864 & 1.152 \\
\hline Tonsil ectopia (mm) & 0.008 & 0.931 & 0.998 & 0.949 & 1.049 \\
\hline Scoliosis & 0.482 & 0.488 & 1.276 & 0.642 & 2.537 \\
\hline \multicolumn{6}{|l|}{ Surgical variables } \\
\hline Tonsil coagulation & 6.101 & $0.014^{*}$ & 3.227 & 1.274 & 8.174 \\
\hline Duraplasty & 0.012 & 0.913 & 1.094 & 0.218 & 5.488 \\
\hline Arachnoid veil transected & 1.437 & 0.231 & 0.521 & 0.179 & 1.513 \\
\hline Post-PFD & 0.090 & 0.764 & 1.230 & 0.318 & 4.753 \\
\hline Post-PFD complications & 1.189 & 0.275 & 1.748 & 0.641 & 4.772 \\
\hline
\end{tabular}

* Significant $p$ value.

coagulation on time to syrinx regression. The number of patients included in our study is higher compared to the previously published studies; due to relatively few numbers of patients undergoing specific surgical steps, the impact of negative associations on outcomes should be interpreted with caution.

\section{Conclusions}

The maximum reduction in syrinx size can be expected within 3 months after PFD for CM-I with a syrinx; however, the syringes continue to regress over time. Tonsil coagulation is associated with early syrinx regression in this cohort. However, the role of surgical maneuvers such as tonsil coagulation and arachnoid veil identification and sectioning in the overall role of CM-I surgery remains unclear.

\section{References}

1. Krieger MD, McComb JG, Levy ML. Toward a simpler surgical management of Chiari I malformation in a pediatric population. Pediatr Neurosurg. 1999;30(3):113-121.

2. Tubbs RS, McGirt MJ, Oakes WJ. Surgical experience in 130 pediatric patients with Chiari I malformations. J Neurosurg. 2003;99(2):291-296.

3. Wu YW, Chin CT, Chan KM, et al. Pediatric Chiari I malformations: do clinical and radiologic features correlate? Neurology. 1999;53(6):1271-1276.

4. Baisden J. Controversies in Chiari I malformations. Surg Neurol Int. 2012;3(suppl 3):S232-S237.

5. Batzdorf U, McArthur DL, Bentson JR. Surgical treatment of Chiari malformation with and without syringomyelia: experience with 177 adult patients. J Neurosurg. 2013;118(2):232242.

6. Genitori L, Peretta P, Nurisso C, et al. Chiari type I anomalies in children and adolescents: minimally invasive management in a series of 53 cases. Childs Nerv Syst. 2000;16(1011):707-718.
7. Haroun RI, Guarnieri M, Meadow JJ, et al. Current opinions for the treatment of syringomyelia and Chiari malformations: survey of the Pediatric Section of the American Association of Neurological Surgeons. Pediatr Neurosurg. 2000;33(6):311-317.

8. Heiss JD, Suffredini G, Smith R, et al. Pathophysiology of persistent syringomyelia after decompressive craniocervical surgery. Clinical article. J Neurosurg Spine. 2010;13(6):729742 .

9. Isu T, Sasaki H, Takamura H, Kobayashi N. Foramen magnum decompression with removal of the outer layer of the dura as treatment for syringomyelia occurring with Chiari I malformation. Neurosurgery. 1993;33(5):845-850.

10. Lee HS, Lee SH, Kim ES, et al. Surgical results of arachnoidpreserving posterior fossa decompression for Chiari I malformation with associated syringomyelia. J Clin Neurosci. 2012;19(4):557-560.

11. Massimi L, Caldarelli M, Frassanito P, Di Rocco C. Natural history of Chiari type I malformation in children. Neurol Sci. 2011;32(suppl 3):S275-S277.

12. Munshi I, Frim D, Stine-Reyes R, et al. Effects of posterior fossa decompression with and without duraplasty on Chiari malformation-associated hydromyelia. Neurosurgery. 2000;46(6):1384-1390.

13. Sekula RF Jr, Arnone GD, Crocker C, et al. The pathogenesis of Chiari I malformation and syringomyelia. Neurol Res. 2011;33(3):232-239.

14. Williams B. The distending force in the production of communicating syringomyelia. Lancet. 1970;2(7662):41-42.

15. Caldarelli M, Novegno F, Vassimi L, et al. The role of limited posterior fossa craniectomy in the surgical treatment of Chiari malformation Type I: experience with a pediatric series. $J$ Neurosurg. 2007;106(3)(suppl):187-195.

16. Chauvet D, Carpentier A, George B. Dura splitting decompression in Chiari type 1 malformation: clinical experience and radiological findings. Neurosurg Rev. 2009;32(4):465470.

17. Chotai S, Medhkour A. Surgical outcomes after posterior fossa decompression with and without duraplasty in Chiari malformation-I. Clin Neurol Neurosurg. 2014;125:182-188. 
18. Durham SR, Fjeld-Olenec K. Comparison of posterior fossa decompression with and without duraplasty for the surgical treatment of Chiari malformation Type I in pediatric patients: a meta-analysis. J Neurosurg Pediatr. 2008;2(1):42-49.

19. Limonadi FM, Selden NR. Dura-splitting decompression of the craniocervical junction: reduced operative time, hospital stay, and cost with equivalent early outcome. J Neurosurg. 2004;101(2)(suppl):184-188.

20. Litvack ZN, Lindsay RA, Selden NR. Dura splitting decompression for Chiari I malformation in pediatric patients: clinical outcomes, healthcare costs, and resource utilization. Neurosurgery. 2013;72(6):922-929.

21. Yilmaz A, Kanat A, Musluman AM, et al. When is duraplasty required in the surgical treatment of Chiari malformation type I based on tonsillar descending grading scale? World Neurosurg. 2011;75(2):307-313.

22. Yundt KD, Park TS, Tantuwaya VS, Kaufman BA. Posterior fossa decompression without duraplasty in infants and young children for treatment of Chiari malformation and achondroplasia. Pediatr Neurosurg. 1996;25(5):221-226.

23. Attenello FJ, McGirt MJ, Gathinji M, et al. Outcome of Chiari-associated syringomyelia after hindbrain decompression in children: analysis of 49 consecutive cases. Neurosurgery. 2008;62(6):1307-1313.

24. Kennedy BC, Nelp TB, Kelly KM, et al. Delayed resolution of syrinx after posterior fossa decompression without dural opening in children with Chiari malformation Type I. $J$ Neurosurg Pediatr. 2015;16(5):599-606.

25. Wetjen NM, Heiss JD, Oldfield EH. Time course of syringomyelia resolution following decompression of Chiari malformation Type I. J Neurosurg Pediatr. 2008;1(2):118-123.

26. Stanko KM, Lee YM, Rios J, et al. Improvement of syrinx resolution after tonsillar cautery in pediatric patients with Chiari Type I malformation. J Neurosurg Pediatr. 2015;17(2):174-181.

27. Wu T, Zhu Z, Jiang J, et al. Syrinx resolution after posterior fossa decompression in patients with scoliosis secondary to Chiari malformation type I. Eur Spine J. 2012;21(6):11431150.

28. Trigylidas T, Baronia B, Vassilyadi M, Ventureyra EC. Posterior fossa dimension and volume estimates in pediatric patients with Chiari I malformations. Childs Nerv Syst. 2008;24(3):329-336.
29. Chotai S, Kshettry VR, Lamki T, Ammirati M. Surgical outcomes using wide suboccipital decompression for adult Chiari I malformation with and without syringomyelia. Clin Neurol Neurosurg. 2014;120:129-135.

30. Heiss JD, Patronas N, DeVroom HL, et al. Elucidating the pathophysiology of syringomyelia. J Neurosurg. 1999;91(4):553-562.

31. Ladner TR, Westrick AC, Wellons JC III, Shannon CN. Health-related quality of life in pediatric Chiari Type I malformation: the Chiari Health Index for Pediatrics. J Neurosurg Pediatr. 2016;17(1):76-85.

32. Tubbs RS, Beckman J, Naftel RP, et al. Institutional experience with 500 cases of surgically treated pediatric Chiari malformation Type I. J Neurosurg Pediatr. 2011;7(3):248256.

\section{Disclosures}

The authors report no conflict of interest concerning the materials or methods used in this study or the findings specified in this paper.

\section{Author Contributions}

Conception and design: Chotai, Wellons. Acquisition of data: Chotai, Chan, Ladner, Hale. Analysis and interpretation of data: Chotai. Drafting the article: Chotai, Wellons. Critically revising the article: Chotai, Bonfield, Naftel, Wellons. Reviewed submitted version of manuscript: Chotai, Ladner, Hale, Gannon, Shannon, Bonfield, Naftel, Wellons. Approved the final version of the manuscript on behalf of all authors: Chotai. Statistical analysis: Chotai. Administrative/technical/material support: Gannon, Shannon. Study supervision: Chotai, Shannon, Bonfield, Naftel, Wellons.

\section{Correspondence}

Silky Chotai: Vanderbilt University Medical Center, Nashville, TN. silky.chotai@vumc.org. 